\title{
Kemenangan Faksi Militan; Jejak Kelam Elit Nahdlatul Ulama'akhir September-Oktober 1965
}

Oleh:

Aan Anshori

Kordinator Jaringan Islam Antidiskriminasi (JIaD) Jawa Timur, mahasiswa S2 Ahwal alSyakhsyiyyah Universitas Hasyim Asy’ari Tebuireng Jombang. Twitter @aananshori

\begin{abstract}
This paper attempts to explain the struggle of militant and moderate factions in the elite body of Jakarta's Nahdlatul 'Ulama (NU) shortly prior to the tragedy of G-30S. The 65 tragedy is the darkest moment in modern Indonesian history that puts NU as one of the dominant actors, especially in Java. NU's involvement as an institution can not be separated from the active role of military NU's elite, as well as the accelerative role of Subchan ZE. With the full support from the military, they build consolidation with the anti-PKI political parties and civil society organizations. That internal movement within NU could be considered as an action of bypassing the NU's elderly who have long been the moderate supporters of Soekarno and PKI. The Militant faction's victory led to the destruction of the PKI in Java that has run very massive with the approval of the local military authorities.
\end{abstract}

Keywords: NU's Elite, Militant Faction

\begin{abstract}
Abstraksi
Tulisan ini mencoba memaparkan pergumulan faksi militan dan moderat di tubuh elit Nahdlatul 'Ulama (NU) Jakarta menjelang dan awal Peristiwa G30S. Peristiwa 65 merupakan lorong paling gelap dalam sejarah Indonesia modern yang menempatkan NU sebagai salah satu aktor dominan, terutama di Jawa. Keterlibatan NU secara institusi tidak bisa dipisahkan dari aktifnya beberapa elit NU yang berlatar belakang militer, ditambah peran akseleratif sosok seperti Subchan ZE. Dengan dukungan penuh militer saat itu, mereka membangun konsolidasi dengan partai politik maupun organisasi masyarakat sipil yang anti PKI. Di internal NU, bisa dikatakan mem-bypass kiai-kiai senior yang memang selama ini menjadi pendukung Soekarno dan moderat terhadap PKI. Kemenangan faksi militan ini menyebabkan proses penghancuran PKI di Pulau Jawa berjalan sangat massif dengan restu otoritas militer setempat.
\end{abstract}




\section{Pendahuluan}

Peristiwa G30S merupakan persoalan yang tidak sederhana. Terutama, menyangkut siapa sebenarnya aktor dibalik meninggalnya 7 perwira angkatan darat pada 1 Oktober 1965 dini hari. Hipotesis para ahli setidaknya merujuk pada empat sosok sebagai dalang; PKI, Soekarno, Soeharto, dan campur tangan asing. Siapapun mastermind-nya, peristiwa tersebut telah berhasil memasukkan Indonesia sebagai salah satu ladang pembantaian manusia. ${ }^{1}$ Jika Pol Pot membutuhkan beberapa tahun untuk melenyapkan ratusan ribu orang, Rezim Indonesia saat itu "hanya" perlu beberapa bulan. ${ }^{2}$ Tidak hanya pembunuhan, berbagai dugaan kuat terjadinya pelanggaran HAM berat juga terdeteksi; pemusnahan, perbudakan, pengusiran atau pemindahan penduduk secara paksa, perampasan kemerdekaan atau perampasan kebebasan fisik lain secara sewenang-wenang, penyiksaan, perkosaan, penganiayaan (persekusi) dan penghilangan orang secara paksa. Elite angkatan darat berperan aktif. ${ }^{3}$ Dalam banyak literatur dan pengakuan, elit militer ini tidak bekerja sendiri. Mereka melibatkan masyarakat sipil dalam menjalankan aksinya. Mereka memberikan training dan mempersenjatai sipil. Bahkan diduga kuat menerapkan strategi agitatif agar kemarahan masyarakat terhadap PKI memuncak. ${ }^{4}$ Organisasi-organisasi yang selama ini antiNASAKOM dan menjadi seteru PKI waktu itu, diduga kuat terlibat dengan berbagai derajat keikutsertaannya.

Di kalangan Nahdlatul Ulama sendiri, sayap paramiliter Ansor punya peran cukup signifikan. Andil elit-elit NU dalam mengkonsolidasi dukungan terhadap sikap militer AD atas G30S merupakan hal penting untuk dilihat. Dinamika di lingkar elit NU di Jakarta menjelang G30S hingga pertengahan Oktober 1965 nampaknya bisa menjadi penjelas massifnya penyerangan terhadap PKI, khususnya di Jawa Timur.

Tulisan pendek yang penyusunannya telah dimulai sejak November-Desember 2014 ini berikhtiar menjelaskan pergerakan elit NU (termasuk Ansor) di Jakarta saat pecah peristiwa G30Shingga dua minggu awal Oktober; hubungan mereka dengan militer AD;

1 Lavene \& Robert, The Massacre in History, Newyork, 1999.

2 Iman Brotoseno, Pembantaian yang Tidak Tercatat, http://blog.imanbrotoseno.com/?p=1498, akses 13 Desember 2014

3 Komnas HAM, Pernyataan Komnas HAM tentang Hasil Penyelidikan Pelanggaran HAM yang Berat Peristiwa 1965-1966, Jakarta, 2012.

4 Nampaknya militer menerapkan strategi tanggung renteng; semakin banyak pihak yang terlibat dalam pembantaian PKI maka semakin banyak pula yang akan menentang kebangkitannya. Strategi ini cukup ampuh, utamanya untuk mengaburkan jejak siapa sponsor utama pembantaian, Asvi W Adam, Pembantaian 1965/1966 Jangan Terulang, dalam R.Cribb, Pembantaian PKI di Jawa dan Bali 1965-1966, 2003. 
friksi yang terjadi di lingkar elit NU; maupun pola dan bentuk transmisi sikap NU ke daerah. Untuk menghormati beberapa nama yang saya anggap senior, saya cukupkan merepresentasi mereka dengan inisial.Secara umum diharapkan tulisan ini bisa menjadikan terang suatu yang didalamnya tidak perlu diselimuti kegelapan.

\section{Luka yang Awet}

Saya perlu menarik agak ke belakang, terutama dalam kerangka memberikan konteks "romantika" NU dan PKI. Dalam percaturan politik Indonesia, hubungan kelompok Islam dan Komunis berlangsung dengan nuansa penuh kecurigaan dari waktu ke waktu. Bruinessen menggambarkan hubungan mereka sebagai "the deepest cultural and political divide in Indonesian society, and the one invested with most emotion and mistrust, is that between Islam and Communism". 5

Kebangkitan NU salah satu bertujuan untuk membendung meluasnya komunisme. ${ }^{6}$ Ideologi ini dituduh antituhan, suatu hal yang 'pantas' dibenci, bahkan jika perlu diperangi.Dalam pandangan konservatif-literal, kekafiran adalah salah satu alasan penumpahan darah. Pandangan seperti ini nampaknya juga menghinggapi NU awal. Tensi yang menegang antara PKI berhadapan dengan PNI dan Masyumi - dimana NU ada di dalamnya- menyebabkan gesekan yang mudah memicu konflik terbuka. Puncak ketegangan pecah, ditandai meletusnya Peristiwa Madiun 1948.

Yang barangkali seringkali absen dalam perbincangan Peristiwa 1948, perseteruan pelik Islam dan Komunis pada 1948 sendiri tidak bisa dikatakan sebagai faktor tunggal. Lebih jauh, ketegangan ini justru berkelindan dengan kuasa internasional, dinamika konfigurasi politik nasional, dan lokal. Dalam tulisan pendeknya, sejarawan Onghokham menjelaskan 3 persoalan struktur yang memicu terjadinya Peristiwa 1948, yakni reorganisasirasionalisasi (rera) $\mathrm{TNI}^{7}$, memburuknya keadaan ekonomi yang membuat diskursus revolusi menjadi condong ke kiri, dan pengaruh perkembangan nasional dan internasional. ${ }^{8}$

5 Martin van Bruinessen, Post-Suharto Muslim Engagements with Civil Society and Democratization, http://www.hum.uu.nl/medewerkers/m.vanbruinessen/publications/Post_Suharto_Islam_and_civil_society.ht m Akses 1 Desember 2014

6 Fealy, G \& McGregor, K 2010, 'Nahdlatul Ulama and the Killings of 1965-66: Religion, Politics and Remembrance', Indonesia, vol. 89, p39.

7 Dengan dalih memodernisasi angkatan bersenjata, pemerintahan Hatta menyetujui konsep re-ra yang bertumpu sepenuhnya pada para perwira terdidik jebolan KNIL di mana menimbulkan kecemburuan di tubuh organisasi para lasykar pejuang kemerdekaan. Analisis mendalam terkait ini dilakukan, salah satunya, oleh DC Anderson, The Military Aspects of The Madiun Affair, Indonesia, Vol.21 (April 1976).

8 Analisa lebih lanjut bisa dilihat dalam, Pemberontakan Madiun 1948: Drama Manusia dalam Revolusi, dalam Onghokham, Rakyat dan Negara, LP3ES, Sinar Harapan, Jakarta, 1983. Ulasan cukup bernas dengan 
Dalam peristiwa yang akhirnya dimenangkan tentara Republik Indonesia ini, korban berjatuhan, baik dari pihak PKI maupun Masyumi-PNI. Orang-orang Masyumi tampak sebagai korban satu-satunya; kadang mereka sebatas dirampok,tapi tidak jarang pula disiksa dan dibantai. ${ }^{9}$ Puluhan hingga ratusan kelompok non-komunis tewas, termasuk para kiai-kiai NU. Pembunuhan disertai kekerasan berlangsung demonstratif dalam bentuk yang mengerikan. Gambaran kekejaman bisa dilihat dari laporan surat kabar Tionghoa;

Semoea pemimpin Masjoemi dan P.N.I ditangkep atawa diboenoeh dengen tidak dipreksa poela. Kakedjeman di kota Madioen djadi memoentjak, koetika barisan 'warok' Ponorogo masoek kota dengen bersendjata revoler dan klewang. Dimana ada terdapet orang-orangMasjoemi, P.N.I. atawa jang ditjoerigaken, zonder banjak tjingtjong lagi lantas ditembak. Belon poeas dengen ini tjara, korban itoe laloe disamperi dan klewangnja dikasi bekerdja oentoek pisahken kepalanja sang korban dari toeboehnja. ${ }^{10}$

Madiun affair semakin mempertebal keyakinan kelompok Islam, tak terkecuali NU, bahwa komunisme adalah musuh inheren-abadi yang tidak hanya perlu dilawan secara politik namun juga fisik. Derajat "kekafiran" PKI dipandang telah memenuhi unsur -apa yang disebut sebagai-kafir harbi atau bughat. ${ }^{11}$

Awal tahun 50an, NU secara konsisten bersikap oposisional terhadap berbagai upaya yang memberikan peluang menguatnya posisi PKI dalam percaturan politik. Kebijakan Soekarno pada 1953 dan 1956 yang memberikan akses lebih kepada para kader PKI di pemerintahan dan militer tidak luput dari kritik NU. Menguatnya PKI dipersepsi telah membuat Soekarno berubah menjadi diktator dan mulai "bergeser" ke kiri hingga menyebabkan Masyumi dibekukan. ${ }^{12}$ Kemesraan ini ditunjukkan Soekarno -bersama militer-

basis memoir AH. Nasution atas Peristiwa Madiun juga dilakukan Coen Holtzappel dalam The Year1948 and The Madiun Affairs- $a$ Year of Cheat and Rumors, http://rozenbergquarterly.com/professional-blindnessand-missing-the-mark-the-year-1948-and-the-madiun-affairs-a-year-of-cheat-and-rumors/Akses

Desember 2014

9 Amos Sukamto, Ketegangan Antar Kelompok Agama Pada Masa Orde Lama Sampai Awal Orde Baru: Dari Konflik Perumusan Ideologi Negara Sampai Konflik Fisik, Jurnal Teologi Indonesia 1/1 (Juli 2013): 25-47.

10 Poeze 1948:217 dalam Amos Sukamto, 2013.

11 Kafir Harbi berarti orang yang tidak beriman dan mendustakan agama serta aktif mengancam keselamatan orang muslim. Sedangkan bughat seringkali dimaknai sebagai pemberontak yang melawan pemerintahan yang sah, lihat Hairus Salim HS, Kelompok Paramiliter NU, LKiS, 2014, hal.158.

12 Yusril Ihza Mahendra, Kebijakan Orde Baru, Masyumi dan Islam, http://yusril.ihzamahendra.com/2008/01/31/kebijakan-orde-baru-terhadap-masyumi-dan-islam/ Akses 1 Desember 2014 
dengan cara membubarkan parlemen melalui Dekrit 5 Juli $1959 .{ }^{13}$ Ini sekaligus menandai berubahnya sistem demokrasi Indonesia: yang awalnya menganut demokrasi parlementer menjadi sistem pemerintahan semi-otoriter; Demokrasi Terpimpin.

\section{Politik Mendua}

NU terbelah menyikapi Demokrasi Terpimpin yang terobsesi menyatukan semua kekuatan politik dibawah jargon politik Nasakom. Kebanyakan kiyai dan elit NU tidak suka dengan kebijakan Sukarno ini kecuali beberapa orang seperti $\mathrm{IC}^{14}, \mathrm{SZ}^{15}$ dan $\mathrm{WC}^{16}$. Para pendukung Sukarno di NU berpandangan masa depan organisasi ini akan terancam jika melawan pemerintah. Mereka juga meyakini keterlibatan NU di pemerintahan akan lebih optimal dalam menghadang kiprah PKI. ${ }^{17}$

Dengan kemampuan politik tingkat tinggi yang dimiliki oleh Kiai Wahab, NU akhirnya memutuskan ikut serta dalam gerbong demokrasi terpimpin. Kehendak Sukarno menyatukan elemen bangsa melalui politik nasakom semakin kokoh dengan masuknya NU. Meskipun demikian, luka sejarah antara Islam - Komunis masih tetap menganga, tidak kunjung padam; seperti api dalam sekam.

Militer -terutama AD- tetap memposisikan kebangkitan PKI sebagai ancaman, seperti halnya faksi militan Islam. Senyampang bersetia dengan Soekaro, diam-diam militer AD terus membangun kekuatan kontra PKI.Berbagai manuver dilakukan elite AD. Salah satunya dengan cara membentuk berbagai badan kerjasama militer masyarakat sipil, seperti pemuda, kelompok tani, wanita, dan ulama. PKI mencium gelagat ini sebagai upaya membangun gerakan konfrontatif melawan dirinya.Partai berlambang palu arit ini keberatan hingga akhirnya badan-badan tersebut tetap dibentuk namun dengan mengikutsertakan PKI. ${ }^{18}$

13 Sebelum dekrit disampaikan, dua orang petinggi TNI AD, A.H Nasution dan R. Rusli bertemu dengan IC dan SZ di Jalan Djokja (sekarang Jl. Mangunsarkoro) untuk mencari tahu respon NU jika dekrit dilakukan.Lihat M.S. Hassan Basri, Dekrit dan Maklumat yang Pernah Ada, Kompas, 27 Juni 2001.

14 Mantan ketua umum PBNU

15 Mantan Menteri Agama

16 Mantan rais aam PBNU

17 HAK, CRCS UGM, "Greg Fealy: Pertengkaran Elit Politik Nahdlatul Ulama (1960-Hingga Kini)", http://crcs.ugm.ac.id/interview/22/Greg-Fealy-Pertengkaran-Elit-Politik-Nahdlatul-Ulama-1960-Hingga-

Kini.html Akses 1 Desember 2014

18 Organisasi koalisi tersebut Badan Kerjasama Pemuda Militer (BPSPM), Badan Kerjasama Ulama Militer (BKSUM), Badan Kerjasama Wanita Militer (BKSW), Badan Kerjasama Tani Militer. Lihat Akbar Tanjung, The Golkar Way, Survival Partai di tengah Turbulensi Politik Era Transisi, hal.141., Hairus Salim, Kelompok Paramiliter NU, hal.37. 


\section{Tensi Meninggi}

Memasuki pertengahan tahun 60an, gesekan PKI dan kelompok Islam - terutama NUsemakin tajam, seiring berjalannya kebijakan landreform. Secara umum, implementasi UU Pokok Agraria yang mengatur distribusi lahan dan UU Pokok Bagi Hasil dilaksanakan oleh sebuah kepanitiaan di daerah. Tidak sedikit daerah yang belum siap menjalankan. Saat panitia terbentuk, tidak jarang terjadi kongkalikong antara panitia, otoritas pemerintah lokal dan militer. Tujuannya, memproteksi kepemilikan lahan demi keuntungan pribadi. Celah permainan militer diretas dengan memanfaatkan SekarDaha(Surat Kordinator Penempatan Daerah), yang memberikan legitimasi masuknya kekuatan militer guna penguasaan perkebunan eks-kolonial di seluruh Indonesia. ${ }^{19}$

Buruknya implementasi landreformdan UUPBH mendapat kritik pedas dari PKI. Di sisi lain, PKI secara diam-diam memanfaatkan situasi ini untuk "menstimulasi" konstituennya agar lebih radikal. ${ }^{20}$ Secara tidak terkontrol, motivasi ini kerap dijalankan menggunakan cara-cara kekerasan, yang sering disebut sebagai aksi sepihak. Aksi ini tidak jarang memperhadapkan PKI dan onderbouwnya dengan kelompok Islam di satu sisi. ${ }^{21}$ Kemarahan kelompok Islam semakin tersulut saat PKI memasukkan kiai sebagai salah satu dari tujuh setan desa karena dianggap resisten terkait implementasi landreform. ${ }^{22}$

\section{Kebangkitan Paramiliter NU}

Salah satu elite NU yang geram terhadap aksi sepihak adalah $\mathrm{YH}^{23}$, pengasuh salah satu pesantren di Jombang. YH mengakui pembentukan sayap paramiliter NU yang bernama Banser (Barisan Ansor Serba Guna) difokuskan untuk mengimbangi aksi sepihak. ${ }^{24}$ Saat

19 Tri Chandra Aprianto, Kekerasan dan Politik Ingatan: Paramiliter Banser dalam Tragedi 1965-1966 di Jawa Timur, dalam Budi Susanto, Politik dan Postkolonialitas, Kanisius, 2003, 37.

20 Ibid,

21 Beberapa aksi sepihak di Jawa Timur terjadi di Kendeng Lembu, Genteng, Banyuwangi, Dampar, Mojang, jember, Kalibaru, Jember, Kediri, Ngawi. Lihat tulisan Agus Sunyoto "Mengenang Partisipasi Politik Banser pada 1965", Jawa Pos 31 Agustus dan 2 September 1996. Bandingkan dengan Rex Mortimer, The Indonesian Communist Party and Land Reform, 1959-1965, Monash Paperon Southeast Asia No.1 (Clayton, Victoria: Monash University, 1972). Hermawan Sulistyo, Palu Arit di Ladang Tebu: Sejarah Pembantaian Massal yang Terlupakan (Jombang-Kediri 1965-1966), KPG, 2000.

22 Agus Sunyoto, opcit., Hermawan Sulistyo, opcit.

23 Putra rais akbar, pernah aktif di militer dengan pangkat letnan satu.

24 Menurut Agus Sunyoto, dengan mengutip KH. Abdurrochim Sidiq, Banser merupakan inisiasi dari GP Ansor Kab, Blitar. Lihat Sunyoto, Mengenang Partisipasi.... opcit. 
bertemu Edi Sudrajat ${ }^{25}$, YH meluapkan kekecewaan atas loyonya negara merespon aksi sepihak tersebut. "Mana jaminan keamanan dari negara? Pemerintahan macam apa ini?". ${ }^{26}$ Bersama $\mathrm{MJ}^{27}$-yang diakui sebagai perumus konsep ideologi Banser-, YH meyakini PKI tidak bisa diatasi dengan cara normal. Saat membaca Mein Kampf YH begitu terinspirasi dengan Panzer Division, satuan khusus beranggotakan anak muda yang dibentuk oleh Hitler untuk menghadapi musuh-musuhnya ${ }^{28}$. Dari divisi itulah nama Banser diambil. Jika dalam aksi sepihak PKI kerap berslogan, "kuasai dulu tanahnya, masalah diurus belakangan", maka Banser mengimbanginya dengan, "Serang dulu, masalah diurus belakangan". 29

Kekuatan Banser sesungguhnya bertumpu pada sayap kepanduan Ansor (Banoe) yang terkenal mempunyai jaringan hingga level kecamatan, bahkan desa. Banoe awalnya tidak digunakan untuk kepentingan politik. Biasanya mereka digunakan untukmenyemarakkan pawai hari besar Islam maupun nasional.Jor-joranpawai kekuatan Islam dan nasionalis berhadapan PKI merupakan hal biasa. ${ }^{30}$ Dengan demikian pendirian Banser telah menggeser fungsi Banoe; dari kepanduan menjadi sayap paramiliter dalam menghadapi aksi sepihak PKI.

\section{G30S: Yang Muda Mengambil Alih}

Menguatnya posisi politik PKI, di satu sisi, serta meruncingnya hubungan kelompok Islam dengan PKI semakin meneguhkan peran strategis $\mathrm{AD}$ memainkan kepentingannya dengan memanfaatkan ketegangan relasi tersebut. Dokumen CIA 8 Oktober 1965 mengungkapkanhasrat militer AD menjadikan tanggal 5 Oktober 1965 sebagai momentum penghancuran PKI dan pengambilankekuasaan negara dari tangan Soekarno. ${ }^{31}$ Dua hari

25 Karir militer dan politik dimulai sebagai Komandan Batalion 515/Tanggul Jember, Pangdam II Bukit Barisan, Pangdam III Siliwangi, Panglima ABRI, Menhankam dan terakhir sebagai Ketua Umum Partai Kesatuan dan Persatuan Indonesia (PKPI).

26 Yusuf Hasyim, Killing Communists, dalam John H McGlynn et.al, Indonesia in the Soeharto Years: Issues, Incidents and Images, Yayasan Obor. Saya mengucapkan terima kasih kepada Prof. Saskia yang berbaik hati mengkopikan tulisan ini.

27 Wartawan Duta Masyarakat, Ketua PWI, dan pendiri PMII.

28 Ibid, hal 2. Lihat juga Yusuf Hasyim, Reposisi Banser di Era Gus Dur, Kompas 14 Februari 2001

29 Yusuf Hasyim, opcit, 17

30 Tri Chandra, opcit, 49-52.

31 Alexander "Rakyat Indonesia Mengutuk Pembunuhan Massal, https://www.google.com/url?sa=t\&rct=j\&q=\&esrc=s\&source=web\&cd=1\&cad=rja\&uact=8\&ved=0ahUKE wjKzO391NLQAhXJPo8KHULIDdgQFggcMAA\&url=http\%3A\%2F\%2Fgelora45.com\%2Fnews\%2FTjania go_MengutukPembunuhanMassal1965.pdf\&usg=AFQjCNFQnNn6kLT-

Frsz6PZQEdh19K2QHA\&sig2=8kkOvPIg6oAHMSfQhIsNkAAkses 14 Desember 2015. Lihat juga Gabriel Kolko, United States Foreign Policy, 1945-1980, New York, 1988. 
sebelum kejadian G30S, tepatnya 28 September,SZE ${ }^{32}$, wakil ketua IV PBNU mengadakan kontak dengan Nasution sambil membawa proposal. Isinya, meminta Kementrian Pertahanan mempersenjatai Pemuda Ansor, Pemuda Islam dan semua organisasi yang antikomunis guna menghancurkan PKI dan Nasakom. ${ }^{33}$

Para elite NU, partai politik dan ormas non-PKI di Jakarta sendiri resah dengan rumor seputar kudeta yang beredar sejak Agustus dan September 1965. ${ }^{34}$ Saat pecah G30S, setidaknya terdapat dua faksi di internal NU; akomodatif-pragmatis dan faksi militan. Beberapa elit NU seperti Kiai WC, Kiai IC, Kiai SZ dan Kiai Masy dan Kiai Dach bisa dimasukkan sebagai pendukung faksi pertama. Sedangkan Kiai $\mathrm{BS}^{35}$, Kiai Mun $^{36}$, Kiai ASA, SZE, Kiai YH, $\mathrm{HB}^{37}, \mathrm{CM}^{38}$ dan $\mathrm{SB}^{39}$ menjadi bagian penting kelompok kedua. ${ }^{40}$

Selain kantor PBNU di Kramat Raya 164, terdapat dua titik lagi yang sering dijadikan tempat berkumpul para elit NU saat putsch G30S; kediaman almarhum Kiai WH di Matraman, dan rumah SZE di Jalan Banyumas ${ }^{41}$. Yang pertama merupakan tempat berkumpulnya kiai-kiai senior, terutama yang berasal dari Jombang. Sedangkan anak-anak muda NU dan aktifis nonmuslim jaringan SZE lebih sering berada di rumah SZE.

32 Lahir di Kepanjen Malang dan besar di Kudus. Memimpin LP Ma'arif Semarang tahun 1953, diangkat sebagai ketua Departemen Ekonomi PBNU saat Kongres NU di Medan 1956, dan menjabat Ketua IV PBNU pada Kongres NU di Solo 1962, lihat Luthfi Thomafi, Mbah Ma'shumLasem: an Authorized Biography of KH. Ma'shum Ahmad, 2007, 157. Dia dikenal tidak hanya dekat dengan jaringan non-NU namun juga militer. Lihat Alexander Tjaniago, opcit.

33 Alexander Tjaniago, opcit.

34 Salim Said, Dari Gestapu Reformasi: Serangkaian Kesaksian, Mizan, Jakarta, 2013

35 Mempunyai pesantren besar di Jombang dan pernah menjabat sebagai Ketua Umum PBNU beberapa kali.

36 Lahir di Mojokerto, sebelum meninggal pernah menjadi anggota Dewan Perancang Pembangunan Nasional, Sekjend Legiun Veteran RI, Ketua Pertanu, Pengurus GP Ansor, Sekjend PBNU. Karir militernya berpangkat mayor dengan NRP 10512. Lihat juga Sembilan Komandan Perang NU, Aula Nov 2012, 58-59., Muchith Muzadi, KH.Munasir Ali: Guruku dan Penuntunku. http://www.nu.or.id/a,public-m,dinamics,detail-ids,4-id,7256-lang,id-c,kolom-t,KH+Munasir+Ali+Almarhum ++ Guruku+dan+Penuntunku.phpxAkses 1 Desember 2014.

37 Pensiunan intelejen

38 Sekretaris Jenderal PP GP Ansor 1965

39 Mantan aktifis organisasi IPNU, PMII, Gerakan Pemuda Ansor, KNPI, Nahdlatul Ulama, Persatuan Wartawan Indonesia (PWI). Mantan wartawan Duta Masyarakat (lama), Pedoman, Pelita dan penulis tetap Republika. Mantan anggota DPR-GR/MPRS dan MPR-RI. Sebelum meninggal, SB juga pernah menjabat sebagai anggota Dewan Pengurus Majelis Ulama Indonesia (MUI), anggota Lembaga Sensor Film (LSF), Ombudsman majalah kajian media dan jurnalisme PANTAU dan anggota Badan Pendiri Yayasan Forum Indonesia Satu (FIS).

40 Fealy, G \& McGregor, opcit.

41 Said Budairy menyebut rumah di Matraman sebagai "posko" sekaligus "pengungsian. Rumah tersebut dianggap aman karena bersebelahan dengan rumah Kolonel Alamsyah yang tiap hari dijaga kendaraan lapis baja, (Said Budairy, Ibu dari Banyak Pemuda Pergerakan, http://sbudairy.blogspot.com/2008/02/ibu-daribanyak-pemuda-pergerakan.html Akses 24 November 2014. Greg Fealy-K.E. Mcgregor, opcit, 42. 
Pada tanggal 30 September malam hari, PP Ansor menyelenggarakan rapat, membahas undangan mengikuti pawai besar-besaran antikapitalisme-birokrat. Pertemuan bertempat di lantai atas Gedung PBNU Kramat Raya 164, berhadapan dengan Kantor CC PKI. Menurut SB, wakil Ketua PP Ansor, beberapa pucuk pimpinan Ansor nampaknya belum mengetahui apa yang sebenarnya terjadi malam itu. Barmawi Alwi, salah satu peserta rapat, sempat bertanya ke forum.

"Apakah diantara anggota pucuk pimpinan Ansor ada yang mendengar seputar kabar Dewan Jenderal?" Tidak ada jawaban definitif soal itu. SB tidak menyinggung adanya putsch malam itu. Rapat selesai sekitar pukul 01.30 dini hari 1 Oktober. $^{42}$

Pascasiaran Kolonel Untung di RRIpagi hari sekitar pukul 07.00, beberapa orang faksi militan NU berkumpul di Jalan Cut Meutia 1,kediaman Kiai Mun dan Kiai YH saat berada di Jakarta. Dalam rapat yang dihadiri -setidaknya- oleh Mun, YH, SB dan MJ itu bertujuan mengetahui dan membahas situasi yang terjadi. ${ }^{43}$

Perlu diketahui,selama berbulan-bulan situasi negara dipenuhi dengan berbagai spekulasi menyangkut kesehatan presiden. Jika sampai Sukarno meninggal, ini akan menyulut konflik terbuka antara kekuatan komunis dan non-komunis. Kekuatiran kelompok non komunis menebal saat kabar penyelundupan senjata dari Cina menyeruak. Mereka segera mengaitkan hal itu dengan kengototan PKI mempersenjatai angkatan kelima. "Kami sangat yakin ini kerjaan PKI. Tidak ada satupun yang menyangkal." 44

Faksi militan setidaknyamengambil bebeberapa respon. Pertama, menyebar kaderkaderterpercaya di kalangan NU -secara diam-diam- untuk mengumpulkan informasi situasi Jakarta. Kedua, sesegera mungkin mengontak elit militer dalam rangka mempersiapkah langkah-langkah jika PKImelakukan balas dendam. Ketiga, mengaktifasi komunikasi darurat dengan cabang-cabang didaerah agar reaksi terhadap PKI bisa terkordinasi dengan baik dan menghindarkan resiko sekecil mungkin bagi anggota NU. ${ }^{45}$

Laporan kader yang disebar menyatakan hanya sebagian kecil saja wilayah Jakarta yang dikuasai G30S.Pada pukul 14.30 GP Ansor memutuskan mengeluarkan duapernyataan publik. Pertama, mencela tindakan yang pada intinya perebutan kekuasaan oleh yang menamakan dirinya Gerakan 30 September. Kedua, menolak dan menentang pembentukan

42 Said Budairy, Subchan ZE Tokoh Muda Aneka Citra, http://sbudairy.blogspot.com/2008/03/subchan-zetokoh-muda-aneka-citra_12.html Akses 1 Desember 2014.

43 Ibid.

44 Wawancara Katharine McGregor dengan AI, pengurus PP Pertanu yang juga cucu KH.Hasyim Asy'ari, dalam Fealy, G \& McGregor, opcit. Lihat juga Mawardi, 1967, 52., Tri Chandra Aprianto, 2003,59.

45 Ibid, 
Dewan Revolusi ${ }^{46}$. Dua poin pernyataan ini hendak disebarkan melalu media massa. Namun, niat ini diurungkan mengingat Pepelrada melarang hampir semua penerbitan untuk mengendalikan atmosfir publik. Setelah gagal, Ansor lalu menemui Brigjend Sugandi menyerahkan pernyataan sikap tersebut. ${ }^{47}$

Elite NU merasa lega saat terdengar kabar AD berhasil melumpuhkan G30S dan telah "mengamankan" situasi pada 1 Oktober malam hari. Yang menarik, segera setelah situasi normal, faksi militan terus berdiskusi, terutama untuk menjadikan kekalahan Untung sebagai kanal penghancuran (to crush) PKI. Faksi militan menyakini saat itu sebagai momentum tepat untuk membalas dendam yang tersimpan lama. Sungguh pun demikian, mereka masih perlu mendapat satu hal; restu militer. ${ }^{48}$ Menurut SB, pada tanggal 1 Oktober, setidaknya ada dua kali pertemuan di kalangan faksi militan; di Jl. Cut Meutia 1 pada pagi hari, dan malam hari bertempat di rumah ketua pengurus wilayah Ansor DKI Jakarta di wilayah Klender. ${ }^{49}$

Yang menarik, pada hari itu juga Pucuk Pimpinan (setingkat pengurus pusat) Gerakan Ansor mengeluarkan sikap resmi menyangkut kejadian 30 September 1965, melalui surat 'Pernjataan No. Ist/PP/1965' tertanggal 1 Oktober 1965 dengan mencantumkan nama JU dan $\mathrm{CM}$, sebagai ketua II dan sekretaris umum. ${ }^{50}$ Dalam pernyataan tersebut tertulis 4 sikap.

Pertama, tetap tegak berdiri dibelakang Presiden/Pemimpin Besar Revolusi/Pahlawan Islam dan Kemerdekaan Bung Karno. Kedua, menentang tindakan kontra-revolusi jang dilakukan oleh apa jang menamakan dirinya "Gerakan 30 September”. Ketiga, menginstruksikan kepada segenap anggauta, kader2 (sic!) dan Pimpinan Gerakan Pemuda Ansor Djakarta Raja chususnja dan diseluruh Tanah air umumnja agar: a. mempertinggi kewaspadaan dengan mendjauhkan diri dari provokasi 2 jang dapat menjerat Gerakan Pemuda Ansor kedalam aksi2kontrarevolusioner "Gerakan 30 September", b. Supaja terus menerus menerus mengadakan kontak dengan pimpinan atasan dan dengan alat2 negara jang menentang gerakan kontra-revolusi tersebut, untuk setiap waktumenunaikan tugas 2 revolusi dan kewadjiban Agama Islam. Keempat, Putjuk Pimpinan Gerakan Pemuda Ansor dalam situasi yang bagaimanapun akan tetap setia pada garis revolusi, kepada tegaknya lima Azimat Revolusi dan kepada adjaran2 Agama Islam. ${ }^{51}$

46 Lahirnya pernyataan kedua karena terdapat 2 nahdliyyin, Fattah Yasin dan Sirajuddin Abbas, masuk dalam list dewan revolusi, namun setelah dikonfirmasi ternyata penyantuman itu sepihak. Keduanya dicomot tanpa pemberitahuan, Lihat Tri Chandra Aprianto, opcit, 60., Mawardi, 1967, 52., Versi lain, ada empat nama wakil NU yang dimasukkan secara sepihak ke Dewan Revolusi, yakni Fattah Yasin, AM. Rahman, Jahya Ubaied, Mahmudah Mawardi. Surat PP GP Ansor ini ditandatangani Jahya Ubaied dan Chalid Mawardi namun tidak banyak pengurus Ansor yang mengetahui perihal surat tersebut, lihat Andree Feillard, Traditionalist Islam and the Army in Indonesia's New Order: The Awkward Moment.

47 Said Budairy, Subchan ZE...opcit.

48 Fealy, G \& McGregor, opcit,

49 Said Budairy, Subchan ZE.... opcit

50 Tanpa tanda tangan maupun stempel

51 Surat ini berkode NA \#172 di Pusat Arsip Australia. Saya berhutang tumpukan terima kasih kepada Prof. Katharine 'Kate' McGregor yang telah memberi scan surat ini. 
Saat pucuk pimpinan Ansor bergerak merespon peristiwa G30S, pun demikian halnya denga n NU -melalui SZE. Komunikasi tingkat tinggi dengan militer pertama kali pascaG30S- dilakukan SZE pada hari yang sama. Aktifis NU yang dikenal flamboyan ini mengontak para perwira "lingkar dalam" Suharto, yakni Umar Wirahadikusuma, Pangdam V Jaya,dan Sutjipto, kepala urusan politik KOTI. Dari keduanya SZE mendapat informasi keterlibatan komunis dalam penculikan para jenderal. SZE diminta membantu mengalahkan G30S dan PKI. Dengan dalih untuk keamanan pribadi, Umar memberi SZE senjata. Belakangan diketahui militer juga memberikan asupan senjata, dana dan training untuk kepentingan mobilisasi anggota NU. ${ }^{52}$

Menurut catatan Alexander Tjaniago, pada tanggal yang sama juga dilakukan pertemuan di markas KOTI dibawah arahan Sutjipto dengan melibatkan 38 ormas Islam dan non-islam. Alexander menyebut pertemuan ini sebagai cikal bakal terbentuknya KAP Gestapu (sebelum akhirnya bermetamorfosis Front Pancasila). Dalam pertemuan tersebut, menurut Alex, telah dihasilkan beberapa keputusan antara lain, menghancurkan PKI sebagai Partai dan melikwidasi/membunuh seluruh Pimpinan-Pimpinan dan Anggota-Anggota PKI dan Organisasi Massa, seperti SOBSI, BTI GERWANI, Pemuda Rakyat, CGMI, HSI, dll., melikwidasi NASAKOM dan menjatuhkan Pemerintahan Presiden Soekarno. ${ }^{53}$

Pada tanggal 2 Oktober, keluarlah pernyataan politik bersama dari para pihak yang mengadakan pertemuan di G-V KOTI sebelumnya. Apakah NU ada di dalamnya, bisa dikatakan ya. ${ }^{54}$ Pada hari itu juga KAP Gestapu dideklarasikan, tentu saja dengan dukungan militer dan CIA. ${ }^{55}$ SZE menjadi ketuanya, Harry Tjan Silalahi menjabat sebagai sekretaris. YH sendiri duduk sebagai salah satu presidiumnya. ${ }^{56}$

52 Ibid, Pada pertemuan tersebut, Umar setuju untuk mempersenjatai pemuda Islam-Front Pancasila termasuk Ansor. Sarwo Edhie melaksanakan keputusan tersebut. Di bawah RPKAD, sekitar 25.000 pemuda dilatih dan dipersenjatai. (Alexander Tjaniago, opcit). Lihat juga Robert Shaplen, Time out of Hand.Revolution and Reaction in Southeast Asia, New York 1969., Salim Said, opcit.

53 Dr. Alexander Tjaniago, Rakyat Indonesia Mengutuk Pembunuhan Massal, http://gelora45.com/news/Tjaniago_MengutukPembunuhanMassal1965.pdf

54 Julius Pour, Gerakan 30 September: Pelaku, Pahlawan \& Petualang, hal. 164

55 Dalam telegram yang dikirim Marshall Green ke Assist. Sec. Bundy from Amb Green. Ref: Deptel 708, Dec 1, 1965, AS diketahui memberikan bantuan Rp. 50 ke KAP Gestapu melalui (Adam?) Malik, tulisannya seperti ini “ 1 . This is to confirm my earlier concurrence that we provide Malik with fifty million rupiahs requested by him for the activities of the Kap-Gestapu movement." http://www.namebase.net/gifs/indo01.gif

56 Ada yang menyebut pertemuan di KOTI yang melibatkan puluhan ormas terjadi pada 1 Oktober 1965. Lihat Alexander Tjaniago, opcit., Brian May (1978), Ulf Sundhaussen (1982), Iwan G Sudjatmiko (1992), Andree Feillard (1995). 
Meskipun demikian, yang agak aneh, menurut Andree Feillard, NU secara formal masih belum menyatakan sikap terkait G30S, apalagi mengaitkannya dengan PKI. ${ }^{57}$ Nampak sekali elit NU masih sangat berhati-hati menyikapi situasi ini. Bagi mereka, kesalahan menentukan sikap akan memicu kerenggangan hubungan NU dengan Presiden Soekarno, suatu hal yang tidak diinginkan oleh elit NU faksi akomodatif. Namun demikian, jika kita percaya apa yang diberitakan Harian Duta Masyarakat 7 Oktober, ternyata pada1 Oktober PBNU sebenarnya telah menyiarkan sikapnya melalui radio. Isinya mengajak nahdliyyin tetap setia terhadap Soekarno, dan meminta militer segera memulihkan ketertiban. ${ }^{58}$ Namun karena media massa dilarang terbit maka edisi tersebut baru bisa ditayangkan pada tanggal 7 Oktober. ${ }^{59}$ Ketidaksolidan elit PBNU juga terasa mendapat afirmasi dari SB. Menurutnya, sikap NU terus digodok di rumah Bu Wahid di bilangan Taman Amir Hamzah bahkan hingga tanggal 2 Oktober. ${ }^{60}$

Pada tanggal 3 Oktober, elite NU mengadakan rapat merespon dinamika politik yang terjadi. Terutama untuk menentukan sikap resmi. Terjadi polarisasi pandangan menyangkut bagaimana NU memandang dugaan keterlibatan PKI dalam G30S. Beberapa kiai senior menyarankan NU menyikap masalah ini dengan hati-hati. Situasi politik yang sangat tidak menentu seperti saat itu dianggap akan membahayakan nahdliyyin dan masa depan partai (NU). Mereka -secara spesifik- menganggap rezim Soekarno dan PKI masih mempunyai cukup kekuatan menghantam siapa saja yang dianggap mengganggu. Nampaknya, pandangan ini terefleksi dari trauma masa lalu dimana Soekarno bisa membubarkan Masyumi dengan dukungan PKI. Kelompok militan berpandangan sebaliknya. Langkah melawan PKI harus dilakukan secara sungguh-sungguh. Mereka yakin sekali keberadaan PKI tidak hanya membahayakan umat Islam namun juga terhadap NU dan kiai. ${ }^{61}$ Kiai Mun menyatakan dalam forum rapat bahwa keterlambatan menghancurkan PKI sama artinya memilih mati. Sebagian besar peserta rapat setuju dengan pendapat Mun. Mereka

57 Feillard, opcit.

58 Ibid. Sepertinya halnya NU yang bersetia kepada Presiden Soekarno, Angkatan Laut Republik mengambil sikap yang sama. Penyataan itu ditandatangani oleh RE.Martadinata. Kompas rencananya menayangkan pernyataan itu pada 2 Oktober namun media dilarang terbit kecuali Harian Berita Yudha, Harian Angkatan Bersendjata dan Harian Rakdjat. Lihat James Luhulima, Menyingkap Dua Hari Tergelap di Tahun 1965, 3032

59 Ibid. Feillard tidak berhasil melacak keberadaan surat asli pernyataan PBNU tersebut.

60 Said Budairy, Subchan Z.E... opcit

61 Fealy, G \& McGregor, opcit. 
menyepakati dua cara menyudahi nasib PKI dan ormas-ormasnya; menyatakan ke publik bahwa PKI dalang G30S, dan memobilisasi kekuatan NU untuk melaksanakan aksi massa melawan komunis. ${ }^{62}$ Sumber lain menyatakan, SZE mendapat mandat merespon situasi dan dinamika yang terjadi, disaat yang sama, para kiai-kiai senior perlu "diungsikan" para kiai dengan alasan keamanan. ${ }^{63}$

Guna mempermudah rantai komando, diputuskan membentuk tim khusus yang bersifat adhoc untuk menangani soal ini. Tim tersebut dinamai Badan Kordinasi Keamanan Jamaah Nahdlatul Ulama, disingkat BKKJNU ${ }^{64}$. Badan ini dipimpin oleh Mun dibantu 3 kordinatorurusan yang masing-masing ditempati oleh Da, SZE, dan AS. ${ }^{65}$ Agaknya, dengan menggunakan PBNU, BKKJ -yang telah dikuasai oleh faksi militan- berkehendak mengontrol gerakan di bawah. Ini terlihat dari salah satu instruksinya ke daerah-daerah.

For further steps in eliminating (menumpas) "30 September Movement" and its henchmen....... wait for and only implement from the Leaders of "NU Community Coordination" [BKKJNU] which formed by PBNU. ${ }^{66}$

Pada tanggal yang sama, PP GP Ansor juga mengeluarkan surat 'INSTRUKSI No. Ist/02/PP/1965 tertanggal 3 Oktober 1965, kali ini dengan menyebutkan ketua umum serta sekretaris umum; CW dan CM namun tanda tangan. ${ }^{67}$

\section{INSTRUKSI}

No. Ist/02/PP/1965

Menjusuli pernjataan Putjuk Pimpinan Gerakan pemuda ANSOR No. Ist/PP/1965, dan pengumuman Putjuk Pimpinan No. Ist/01/PP/1965 masing2 tertanggal 1 Oktober 1965, maka dengan ini kami instruksikan kepada segenap anggauta, kader2 dan pimpinan2 Gerakan Pemuda Ansor di Djakarta Raya chususnja dan diseluruh tanah air umumnja, agar:

1. Tetap mempertinggi kewaspadaan terus menerus dan mendjaga agar djangan sampai mmelibatkan diri, baik perorangan maupun organisasi kedalam aksi2 kontra revolusioner dari apa jang menamakana dirinja 'GERAKAN 30 SEPTEMBER'.

2. Dengan djalan bagaimanapun, membantu pihak ABRI memulihkan keamanan dan mendjaga keutuhan bangsa serta menjelamatkan Revolusi dibawah pimpinan Presiden/Pahlawan Islam dan Kemerdekaan Bung Karno.

62 Greg Fealy, Killing for God, Inside Indonesia, Vol.99, Jan-March 2010.

63 Ada 3 orang hadir dalam pertemuan tersebut; Masy, IC, dan Syaf Manaf. Lihat Feillard, opcit.

64 Lihat PBNU, “Surat Keputusan,” 3302/tanfd/B/X-'65.

65 Fealy, G \& McGregor, opcit.

66 Ibid., Lihat juga PP GP Ansor, "Instruksi”, Ist/02/PP/1965, 3 Oktober 1965

67 Di bawah nama mereka ada tulisan 'Disalin sesuai dengan aslinja oleh:” SS yang tertulis sebagai "Sekretariat P.P.G.P. Ansor” dengan tanda tangan dan berstempel. 
3. Untuk langkah2 selandjutnya dalam rangka menumpas "GERAKAN 30 SEPTEMBER"dan antek2nja serta langkah pengamanan hendaknja menunggu dan hanja melaksanakan instruksi dari Pimpinan "Kordinasi Djamaah Nahdlatul Ulama" jang telah dibentuk oleh PB.N.U pada tingkat pusat dan akan dibentuk oleh Pimpinan2 Partai di daerah2 menurut tingkat2 yang sederadjat.

4. Demikianlah harap instruksi ini dilaksanan dengan sebaik-baiknja.

Meskipun surat BKKJNU dibuat mengatasnamakan PBNU namun diduga kuat hal ini tanpa berkonsultasi terlebih dahulu dengan IC ataupun WC. IC dikabarkan tidak di Jakarta. Keberadaannya tidak diketahui sekitar seminggu. IC berhasil ditemui setelah beberapa mahasiswa utusan faksi militan mendatanginya saat sidang konstituante tanggal 8 Oktober di Bogor. Di sana, mereka meminta IC meneken surat tersebut. ${ }^{68} \mathrm{WC}$ pun demikian, rais aam ini dikabarkan sering pulang kampung karena alasan kesehatan. ${ }^{69}$ Faksi akomodatif benar-benar tidak berkutik membendung laju sayap militan NU pada minggu awal Oktober. Dalam prakteknya tidak jarang faksi militan melakukan 'bujuk rayu dan tipu daya"70 untuk memastikan kelancaran gerakannya, misalnya -yang agak mencengangkan- ada beberapa surat atas nama PBNU dikeluarkan dengan cara menduplikasi tanda tangan IC maupun pemimpin PBNU lainnya. ${ }^{71}$

Meski "restu" militer telah dikantongi SZEsaat menemui Umar Wirahadikusuma dan Sutjipto pada 1 Oktober, nampaknya faksi militan masih merasa perlu memperkuat lagi sinyal dari tentara. Faksi ini mengirim utusan menemui Nasution, bukan Suharto.

Sebagaimana diketahui, dalam panggung sinetron G30S, Suharto memang seperti bintang utama namun bagaimanapun juga dia tetap harus "mencium tangan" Jendral Nasution, baik secara kepangkatan, pengalaman maupun kemampuan. Dalam rantai komando, jika A. Yani berhalangan, Suharto menganggap Nasution lah yang berwenang. Faksi militan NU sepertinya memahami betul peta perwira militer non-komunis saat itu. Perlu dicatat, hampir semua tokoh kunci di faksi militan NU mempunyai latar belakang ketentaraan. Mereka adalah pilar utama IKABEPI (Ikatan Bekas Pedjuang Islam).

68 Feillard, opcit.

69 Dia sendiri tidak terlibat aktif dalam upaya penghancuran PKI oleh NU, meskipun beberapa kali dilapori dan dimintai persetujuan oleh faksi militan yang dimotori oleh SZE, Zam, Mun, YH dan CM. WC meyakini keterlibatan PKI namun seruannya untuk tetap mempertahankan Soekarno sedikit mengimbangi agresifitas faksi militan. Lihat Greg Fealy, Wahab Chasbullah, Tradisionalism and the Political Development of Nahdlatul Ulama, catatan kaki 94.

70 Terjemahan dari cajoling and deceit, lihat Fealy and McGregor, opcit, 45.

71 Ibid 
Adalah Kiai Mun yang menemui Nasution di RSPAD saat jenderal ini dalam proses pemulihan kakiakibat tertembak pada Peristiwa G30S. Kiai asal Mojokerto ini bukan sembarang kiai. Mun barangkali satu-satunya kiai di NU yang menyandang pangkat kemiliteran tertinggi sebelum pensiun ${ }^{72}$. Ayah RM ini merupakan sahabat Kiai Wahid Hasyim. Saat Kiai YH dan Kiai AC, putra hadratus syaikh, aktif di militer, Kiai Mun merupakan komandan sekaligus pembimbing mereka.Dalam pertemuan tanggal 3 Oktober itu Nasution "merestui" keinginan faksi militan NU melancarkan upaya sungguh-sungguh dalam melawan PKI. ${ }^{73}$

Di saat yang sama beberapa elit faksi militan NU melanjutkan briefing bersama para perwira militer AD di markas KOTI. Di sana, mereka mendapat "penjelasan" seputar G30S, versi AD tentunya. Untuk meyakinkan forum, militer juga memutar rekaman "pengakuan"74 dari pelaku G30S, sambil meminta dukungan dari forum, terutama dari NU. Meski ada beberapa individu ${ }^{75}$ dari NU yang mendukung PKI namun nampaknyamiliter menyadari jika dibanding dengan AD sendiri, NU relatif masih steril dari infiltrasi PKI.

\section{Bersuara Tanpa Tanda Tangan}

Dengan dukungan militer, pada tanggal 4 Oktober SZE bersama seluruh komponen KAP Gestapu menyelenggarakan rapat akbar menuntut pembubaran PKI dan organisasi yang dianggap onberbouwnya. Rapat akbar yang bertempat di Taman Untung Suropati Menteng itu diikuti setidaknya oleh 42 organisasi. Sore hari, Soeharto menggunakan RRI untuk menyiarkan keterlibatan PKI dalam G30S.Saya kira inilah untuk pertama kalinya "keterlibatan" PKI diumumkan ke publik oleh militer. ${ }^{76}$

Pada hari yang sama, "sikap resmi” NU akhirnya dikeluarkan dan dipublikasikan melalui radio ${ }^{77}$. Dalam pernyataannya, "NU" menuntut pembubaran PKI dan onderbouwnya

72 Pangkatnya Mayor AD. Dia pernah memimpin kesatuan yang cukup disegani di Jawa Timur, Batalyon Condromowo.

73 Fealy, G \& McGregor, opcit.

74 Terkait bagaimana cara pengakuan didapat, lihat Stanley, Penggambaran Gerwani Sebagai Kumpulan Pembunuh dan Setan (Fitnah dan Fakta Penghancuran Organisasi Perempuan Terkemuka, 1999. Lihat juga Saskia E Wieringa, Kuntilanak Wangi: Organisasi-Organisasi Perempuan Indonesia Sesudah 1950, 1998.

75 Untuk detilnya, baca biografi: Hasan Raid, Pergulatan Muslim Komunis: Biografi Hasan Raid (Yogyakarta: LKPSM dan Syarikat, 2001) dan Achmadi Moestahal, Dari Gontor ke Pulau Buru: Memoar H. Achmadi Moestahal (Yogyakarta: Syarikat, 2001)

76 Transkrip Berita Yudha 5 Oktober, lihat Selected Documents Relating to the 'September $30^{\text {th }}$ Movement"and Its Epilogue, Indonesia, No.1 (Apr., 1966) pp. 131-204, SoutheastAsia Program Publication at Cornell University.

77 Sikap NU ini dibacakan oleh SZE didukung oleh Partai Katholik, IPKI, dan PSII di KOSTRAD. Elemen ini juga m mendesak agar militer segera bertindak. Lihat Selected Documents... opcit. pp203-204 
serta meminta agar media massa yang berafiliasi dengan PKI ditutup. ${ }^{78}$ Yang menarik, pernyataan sikap yang rumusannya dibuat atas restu SZE diluncurkan tanpa sepenuhnya ditandatangani oleh pemimpin NU. ${ }^{79}$

Pagi 5 Oktober 1965 jenazah para jenderal dikebumikan. Dalam pidatonya, Suharto mengungkapkan bela sungkawa sambil menuduh PKI terlibat dalam G30S. Pernyataan sikap "NU" yang dibuat dan diumumkan SZE sehari sebelumnya baru dimintakan tanda tangan saat elit NU menghadiri pemakaman. Mereka - Kiai Dach dan Kiai Masy- didatangi dua orang dari faksi militan, keduanya punteken. ${ }^{80}$ Surat penyataan ini juga menyertakan tanda tangan dari badan otonom yang ada di bawah NU.

Malamnya sekitar pukul 20.00 beberapa anggota faksi militan menuju RRI guna menyiarkan pernyataan sikap NU. Menurut catatan SB, dengan menggunakan mobil VW, rombongan yang terdiri dari Mun, YH, CM, SB dan dua orang mahasiswa, yakni RM dan UW berangkat dari Matraman menuju Jl. Banyumas untuk menjemput SZE terlebih dahulu. Sesampai di komplek RRI, rombongan sempat tidak diperbolehkan masuk. Setelah dijelaskan dan -tentu saja- mendapat izin dari Soeharto, mereka akhirnya ditemui oleh Sugandhi dan Yusuf Sirath. Kedua perwira ini memang ditugaskan Suharto menguasai RRI. SZE sedikit bersikeras agar diperbolehkan membacakan langsung pernyataan sikap tersebut melalui corong RRI namun tidak izinkan. Pernyataan sikap akhirnya dibacakan penyiar satu jam kemudian. ${ }^{81}$

Untuk memastikan instruksi penghancurkan komunis berjalan lebih massif, faksi militan yang telah menguasai NU memerintahkan orang-orang kepercayaannya melakukan turba ke daerah. SZE kembali memegang peranan krusial dalam hal ini. Dengan membawa helikopter milik angkatan laut, dia dikabarkan terbang langsung ke wilayah eks Karesidenan Besuki, bertemu para kiai. Kenapa wilayah eks karesiden Besuki? Sangat mungkin daerah ini dikenal sebagai salah satu basis komunis sekaligus kantong NU militan di Jawa Timur. Aksi sepihak banyak terjadi di wilayah ini. ${ }^{82}$

SZE menemui Kiai ASA. Kiai kharismatik asal Situbondo ini memang sejak awal tidak cukup simpatik terhadap kebijakan faksi akomodatif yang dianggap tidak tegas terhadap

\footnotetext{
78 Misalnya Harian Rakjat, Warta Bhakti, Bintang Timur, Kebudajaan Baru, Ekonomi Nasional , Gelora Indonesia, dll. Lihat Selected Documents.... opcit. pp204

79 Feillard, opcit, catatan kaki 16. Harian Berita Yudha, 6 Oktober 1965 memberitakan pernyataan sikap NU secara lengkap tertanggal 5 Oktober. Lihat juga Selected Documents.... op cit.

80 Salah satu yang meminta tanda tangan adalah YH. Proses penandatanganannya di bawah pohon Kamboja, lihat Andree Feillard, NU vis a vis Negara, hal. 75

81 Said Budairy, opcit.

82 Agus Sunyoto, Mengenang Partisipasi Politik Banser.... opcit.
} 
PKI. ASA merupakan tokoh terpandang Jawa Timur. Dia -yang juga merupakan yunior Rais Akbar NU saat belajar di Syaikhona Kholil Bangkalan- mempunyai peran sentral dalam NU awal. Sewaktu Mbah Hasyimberistikharah untuk mendirikan NU, Syaikhona Kholil menyuruh ASA berjalan kaki dari Bangkalan ke Tebuireng. ASA mendapat mandat menyerahkan tongkat dan tasbih ke mbah Hasyim. Kedua benda ini -oleh mbah Hasyimdianggap sebagai sinyal (isyarah) NU boleh didirikan. ${ }^{83}$ Selain sowan ke Kiai ASA, SZE juga mengunjungi kiai ZM, pengasuh pesantren besar di Paiton Probolinggo. ${ }^{84}$

\section{Kuasa Gelap Melalui Media}

Sejak pecahnya G30S, Suharto melarang seluruh media terbit hingga 7 Oktober, kecuali Berita Yudha, Angkatan Bersenjata dan Harian Rakyat. ${ }^{85}$ Dengan demikian militer lebih leluasa mengontrol "kebenaran" terkait kejadian G30S, terutama menyangkut bagaimana para jenderal ini dibunuh. ${ }^{86}$ Militer begitu sistematis mengatur pemberitaan

83 Misrawi, Zuhairi. Hadratussyaikh Hasyim Asy'ari: moderasi, keumatan, dan kebangsaan. Penerbit Buku Kompas, 2010.

84 Tri Chandra A, opcit., hal.62

85 Tanggal 3 Oktober, Harian Rakyat tidak terbit. Aktifis dan pendukungnya diburu, ditangkap dan dihilangkan, bahkan dibunuh. Lihat Arif Zulkifli, Seri Buku Tempo: Lekra dan Geger 1965, Jakarta: Kepustakaan Populer Gramedia, 2014

86 Berikut ini pemberitaan yang diambil dari makalah Stanley, opcit.. Lihat juga Saskia E Wieringa, Penghancuran Gerakan Perempuan di Indonesia, 1999., Ben Anderson, How Did the Generals Die?, Indonesia, vol.43 (April 1987), 109-134, Cornell University. “... Letnan Tendean mengalami luka tusuk di dada kiri dan perut, lehernya digorok. Kedua matanya dicungkil,”, (Berita Yudha, 9/10/1965)., “... Perempuan-perempuan tak dikenal mendatangi rumah para Pahlawan kita, dengan memakai mukena seakanakan mereka orang-orang Muslim. Gerak-gerik mereka menimbulkan kecurigaan, karena jelas mereka itu orang-orang Gerwani. ....(Angkatan Bersenjata, 11/10/1965)., “... Sesudah tertangkap ia [Tendean] disiksa dengan sangat kejam, karena para penculik ini mengira ia Jenderal Nasution. Ia kemudia diserahkan kepada sukarelawan-sukarelawan Gerwani lalu dengan tangan dan kaki terikat, Tendean menjadi permainan cabul setan-setan perempuan Gerwani, yang perbuatan mereka merendahkan martabat wanita Indonesia." (AB, 11/10.1965)., “... sukarelawan-sukarelawan Gerwani telah bermain-main dengan para jenderal dengan mengosok-gosokkan kemaluan mereka ke kemaluan sendiri”, (AB, 11/101965)., “.. mata dicungkil, dan sementara itu ada yang dipotong kemaluan mereka.”, (Berita Yudha, 11/10/1965)., “ .. Bahkan menurut sumber yang dapat dipercaya, orang-orang Gerwani menari-nari telanjang di depan korban-korban mereka, tingkah laku mereka mengingatkan kita pada upacara kanibalisme yang dilakukan suku-suku primitif berabad-abad yang lalu. Marilah kita serahkan kaum wanita untuk mengadili moral kewanitaan orang-orang Gerwani, yang bermoral bejat lebih buruk dari binatang,“, (Duta Masyarakat, 12/10/1965)., " Bagaimana kita harus menceritakan pada anak-anak perempuan kita [atas pemberitaan di atas]?” (Api Pancasila, 12/10/1965)., "Siapa akan mengira bahwa latihan-latihan di Lubang Buaya itu akan menghasilkan buayabuaya dan bukan Srikandi-Srikandi sejati, yang akan berjuang bahu membahu dengan kaum laki-laki untuk revolusi kita?," (AB, 16/10/1965)., “Tidakkah Gerwani telah mengkhianati keluarga, bangsa, rakyat Indonesia dan Revolusi Indonesia?”, (AB, 28/10/1965). Lihat juga Ben Anderson, opcit. 
dengan cara mengglorifikasi peranPemuda Rakyat dan Gerwani. ${ }^{87}$ Kedua organisasi ini dibuat seolah-olah menjadi aktor utama pembantaian jenderal dengan bumbu kekejaman dan tindakan pelecehan seksual yang terkesan mencampuradukkan fiksi dan realita. Meskipun hasil visum et repertum jenderal membantah penggambaran jenazah korban sebagaimana pemberitaan media massa namun publik terlanjurmempercayai apa yang sudah dirancang militer dan pendukungnya. ${ }^{88}$

Harian Duta Masyarakat termasuk yang mengamini berita apa kata Harian Angkatan Bersenjata dan Berita Yudha. Pada tanggal 7 Oktober, misalnya, harian milik NU ini menyiarkan berita seruan pengganyangan antek-antek PKI dalam tajuknya:

di tajuk rencananya tanggal 7 Oktober 1965 menyatakan: bahwa keputusan "yang paling tepat" dan paling baik adalah memberantasnya (para komunis), "akar-akarnya", komplotannya, pembelaannya, dan semua yang bertindak bersamanya, baik secara terbuka atau tersembunyi (Duta Masyarakat 7 Oktober 1965 dikutip oleh Feillard 1999:72)

Kemarahan publik terhadap PKI sudah tidak bisa dikendalikan lagi, termasuk di kalangan nahdliyyin. Eskalasi kekerasan terhadap PKI semakin meningkat. Berbagai properti milik PKI dibakar dan jarah. Tidak ketinggalan pula Kantor CC PKI di kawasan Kramat Raya pada tanggal 8 Oktober. Aksi dilakukan oleh massa yang dimobilisasi oleh KAP Gestapu.

Yang mengagetkan, pada pertengahan Oktober 1965 ditengah "kemenangan" faksi militan melancarkan gerakan pembasmian PKI dan onderbouwnya, PBNU bersikap ambigu. NU menyiarkan seruan kepada seluruh media yang berafiliasi ke NU untuk, "menjaga hubungan baik dengan PKI, Soekarno dan tidak menyalahkan Angkatan Udara serta ABRI

87 Kesimpulan Saskia E Wieringa (1998 \& 1999) Gerwani tidak terlibat dalam G30S. Keberadaan mereka di Lubang Buaya sebagai sukarelawan untuk persiapan peningkatan konfrontasi dengan negara "boneka" Inggris, Malaysia. Pelatihan ini untuk memenuhi seruan Dwikora Presiden Soekarno. Tidak hanya pemudapemudi komunis yang dilatih di Lubang Buaya, setelah tanggal 1 Oktober direncanakan pemuda NU juga diharapkan akan hadir dan berlatih di tempat ini. Lihat Stanley, opcit., Saskia E Wieringa (1998\&1999), opcit., Lihat juga Wisnu Djajengminardo, Kesaksian (Memoir Seorang Kelana Angkasa), Bandung, $1977 .$. Berbagai pemberitaan yang memojokkan Gerwani dan Pemuda Rakyat merupakan hasil manipulasi pengakuan dengan menggunakan kekerasan. Lihat Stanley, opcit., Saskia E Wieringa, opcit.

88 Visum terhadap para jenderal atas permintaan pribadi Soeharto dimulai pukul 16.304 Oktober sampai 00.30 5 Oktober. Hasilnya diserahkan langsung ke Suharto pada hari itu sebelum pemakaman. Hasil visum menunjukkan tidak ada siksaan sebagaimana yang diberitakan. Alat kelamin semua Jenderal masih utuh. Satu jenderal teridentifikasi belum disunat. Pencungkilan mata tidak bisa ditemukan saat otopsi. Merupakan tanda tanya besar kenapa Suharto membiarkan media memberitakan hal salah terkait kondisi jenderal, sedangkan Suharto memegang hasil otopsinya?. Presiden Soekarno pernah gusar terhadap pemberitaan manipulatif ini. Dia mengumpulkan semua wartawan pada Desember membahas hasil otopsi, lihat Ben Anderson, opcit. 
secara umum". ${ }^{89}$ Sungguh pun demikian, seruan ini tidak cukup ampuh meredam praktek pembantaian massif yang mencapai puncaknya pada pertengahan Oktober hingga menjelang Desember.

\section{Roadshow ke Daerah; Mendistribusikan Perintah}

Bukti-bukti menunjukkan elite Ansor terus mengambil inisiatif untuk mengintensifkan komunikasi ke daerah-daerah. Bahkan mereka memerintahkan beberapa elitnya mengambil jalan darat dari Jakarta hingga Jawa Timur, termasuk Madiun, Kediri dan Malang. Di setiap kota yang dilewati, rombongan ini tidak hanya mensosialisasikan sikap keras NU namun juga mendorong elemen antikomunis, terutama dari kalangan muda Ansor, segera merespon secara "konkrit". Tim ini selalu mewanti-wanti agar kekuatan non-komunis di daerah terus berkomunikasi dengan militer setempat. Setibanya di Jember, disamping berkordinasi dengan Ansor setempat, tim ini juga bertemu Kia AS, salah satu tokoh NU berpengaruh di Jember. Untuk menjaga hal-hal yang tidak diinginkan, tim dikawal ketat oleh anggota Banser. Tim juga membawa pistol pemberian kesatuan elite AD. Kendati demikian, hingga pulang ke Jakarta, pistol tersebut tidak pernah digunakan. ${ }^{90}$

Situasi politik di Jakarta juga mendorong Pangdam Jawa Timur, Basuki Rachmad, melakukan sosialisasi Peristiwa G30S versi tentara. Basuki hadir dalam pertemuan kiai yang diinisiasi Wijono, Gubernur Jawa Timur Wijono. Sedikitnya 30 kiai se-Jawa Timur hadir, diantaranya Kiai ASA (Situbondo), Kiai MA (Kediri), Kiai Dj (Kencong), Kiai ZM (Paiton), termasuk KS salah seorang Ketua PW Ansor Jawa Timur. Dalam forum tersebut, Basuki Rachmat 'curhat' bahwa AD telah difitnah dan didzolimi PKI sehingga kehilangan tujuh putra terbaiknya. Dengan cerdiknya, Basuki mencoba menarik simpati puluhan kiai dengan mengatakan "Karena itu saya minta fatwa para kyai. Apa yang yang harus kami lakukan sekarang?". Suasana seperti itu membuat KH. ASA mengambil sorban dan mengikat erat di kepalanya.

Dalam kemarahannya, Kiai ASA "berfatwa" PKI halal darahnya. Dia secara tegas menyatakan nyawa ketujuh jenderal tersebut harus "ditebus" oleh orang-orang PKI. ${ }^{91}$ Dengan melihat kredibilitas kekiyaian ASA sebagai santri utama Kiyai Hasyim Asyari, secara

89 Feillard, opcit, catatan kaki 19. Lihat juga, Surat PBNU, Pedoman Politik Pemberitaan Harian NU, 14 Oktober 1965 yang dikirim ke 5 media milik NU.

90 Tri Chandra, opcit, 63.

91 Tri Candra A, opcit, 66. Lihat juga Choirul Anam (ed.), K.H.R. As'ad Syamsul Arifin, Riwayat Hidup dan Perjuangannya, 1994, 67-68 
psikologis, fatwanya sangat mempengaruhi kiai lain yang hadir - yang secara keilmuan bisa dianggap "lebih rendah" dibanding ASA.

Merasa mendapat dukungan luarbiasa dari kiai besar seperti ASA, Basuki Rachmad meminta bentuk konkrit dukungan apa yang bisa didapat AD. ASA langsung menjawab sambil menuding KS, "Jangan kuatir, ini ada KS, dia ini Ketua GP Ansor Jawa Timur yang bisa mengerahkan ribuan pasukan Ansor". Pertemuan Grahadi itu menghasilkan kesepakatan bulat mendukung TNI Angkatan Darat melakukan pembersihan PKI. ${ }^{92}$

Perlu dicatat, bahwa militer AD juga menerjunkan tidak sedikit personilnya untuk mengkonsolidasi dan mensosialiasi 'kebenaran' G30S. Menggunakan model turba yang dilakukan Ansor. Rekrutmen biasanya bersifat khusus, memprioritaskan personil yang, misalnya, pernah belajar di pesantren dan punya pengetahuan mendalam terkait NU. ${ }^{93}$

Kordinasi yang sangat kuat di internal kelompok non-komunis, ditambah intervensi dan dukungan militer merupakan penjelas terjadinya eskalasi pembantaian orang yang dituduh PKI di Jawa Timur sepanjang Oktober-Desember 1965. Sekitar 54.000 orang yang dituduh PKI terbunuh ekstrayudisial. ${ }^{94}$ Brutalnya pembantaian di Jawa Timur menyebabkan pemerintah gusar. Soeharto meminta YH untuk menghentikan Ansor yang mengamuk. "What is going on with Ansor amuck? I want this stopped!" ${ }^{95}$ Pasca mendapat laporan dari komisi pencari fakta terkait Korban 1965, Soekarno - di sebuah pertemuan yang juga dihadiri oleh CM- sangat gusar atas peran Ansor di Jawa Timur. ${ }^{96}$ Meski pada Januari, militer telah meminta "dengan tegas" supaya pembantaian dihentikan, namun praktek perburuan dan pembantaian orang-orang yang dituduh PKI tetap dilakukan, baik oleh militer maupun paramiliter NU.

\section{Penutup}

Ketegangan antara NU-PKI sebagai sebuah ideology maupun organisasi memang tidak pernah surut. Peristiwa Madiun menorehkan luka mendalam dalam diri NU dan umat Islam Indonesia. Saat panggung politik tahun 50an lebih berpihak ke PKI, bibit perpecahan di internal NU sudah mulai muncul dalam bentuk faksi akomodatif-pragmatis dan militan.

92 Ibid.

93 Militer aktif yang disusupkan untuk "memotivasi" masyarakat akar rumput ini berbekal semangan "pelihara teritorial", Tri Chandra A, opcit.,

94 Tri Chandra, opcit, 25. Lihat juga Hermawan Sulistyo, opcit.

95 Yusuf Hasyim, opcit, 17.

96 Feillard, opcit. Komisi ini dipimpin oleh dr. Sumarno (Mendagri), Oei Tjoe Tat (Partindo), Chalid Mawardi (NU), dan Brigjend Sunarso (KOTI), lihat Marwati DP-Noegroho Notosusanto, Sejarah Nasional Indonesia VI: Zaman Jepang dan Zaman Republik Indonesia, 544 
Maraknya aksi sepihak yang dianggap bisa membahayakan eksistensi kiai di daerah, serta lunglainya negara memberikan perlindungan pada umat Islam memicu faksi militan NU mengambil "inisiatif” mendirikan sayap paramiliter. Faksi militan NU yang terdiri dari kiaikiai dan politisi muda menganggap lambatnya respon kiai-kiai senior dalam faksi akomodatif berpotensi membahayakan organisasi dan konstituen, bahkan nasib umat Islam pada umumnya. Setelah bisa "menguasai" PBNU melalui BKKJ NU, faksi militan terus bergerak mengkonsolidasi kebijakan mendukung militer menghancurkan PKI ke daerah-daerah.

\section{Daftar Pustaka}

Levene, Mark, and Penny Roberts. The massacre in history. Vol. 1. Berghahn Books, 1999. Iman Brotoseno, Pembantaian yang Tidak Tercatat, http://blog.imanbrotoseno.com/?p=1498, akses 13 Desember 2014

Komnas HAM, Pernyataan Komnas HAM tentang Hasil Penyelidikan Pelanggaran HAM yang Berat Peristiwa 1965-1966, Jakarta, 2012.

Cribb, Robert. "The Indonesian killings of 1965-1966: studies from Java and Bali." (1991).

van Bruinessen, M. M. "Post-Suharto Muslim engagements with civil society and democratization." (2007).

Fealy, Greg, and Katharine McGregor. "Nahdlatul Ulama and the Killings of 1965-66:

Religion, Politics, and Remembrance." Indonesia 89 (2010): 37-60.

Anderson, David Charles. "The military aspects of the Madiun Affair." Indonesia 21 (1976): $1-63$.

Ham, Ong Hok. "Rakyat dan Negara.", Jakarta: Pustaka Sinar Harapan (1991).

Coen Holtzappel, The Year1948 and The Madiun Affairs- a Year of Cheat and Rumors, http://rozenbergquarterly.com/professional-blindness-and-missing-the-mark-the-year-1948and-the-madiun-affairs-a-year-of-cheat-and-rumors/

Sukamto, Amos. "KETEGANGAN ANTAR KELOMPOK AGAMA PADA MASA ORDE LAMA SAMPAI AWAL ORDE BARU: Dari Konflik Perumusan Ideologi Negara Sampai Konflik Fisik1." Jurnal Teologi Indonesia 1 (2013): 25-47.

Yusril Ihza Mahendra, Kebijakan Orde Baru, Masyumi dan Islam, http://yusril.ihzamahendra.com/2008/01/31/kebijakan-orde-baru-terhadap-masyumi-danislam/ Akses 1 
Greg Fealy: Pertengkaran Elit Politik Nahdlatul Ulama (1960-Hingga Kini)", http://crcs.ugm.ac.id/interview/22/Greg-Fealy-Pertengkaran-Elit-Politik-Nahdlatul-Ulama1960-Hingga-Kini.html Akses 1 Desember 2014

Salim, Hairus. "Kelompok paramiliter NU." (2004).

Tanjung, Akbar. The Golkar Way. Gramedia Pustaka Utama, 2007.

Susanto, A. Budi. Politik dan postkolonialitas di Indonesia. Kanisius, 2003.

Sulistyo, Hermawan. Palu arit di ladang tebu: sejarah pembantaian massal yang terlupakan, Jombang-Kediri, 1965-1966). Pensil-324, 2011.

Agus Sunyoto “Mengenang Partisipasi Politik Banser pada 1965”, Jawa Pos 31 Agustus dan 2 September 1996 Mortimer, Rex Alfred. Indonesian Communist Party and land reform, 1959-1965. Vic., Centre of Southeast Asian Studies, Monash University, 1972.

McGlynn, John H., and Hermawan Sulistyo. Indonesia in the Soeharto years: issues, incidents and images. NUS Press, 2007.

Yusuf Hasyim, Reposisi Banser di Era Gus Dur, Kompas 14 Februari 2001

Kolko, Gabriel. Confronting the Third World: United States Foreign Policy, 1945-1980.

Pantheon, 1988.

Thomafi, Muhammad Luthfi. Mbah Ma'shum Lasem. PT LKiS Pelangi Aksara, 2007.

Salim Said, Dari Gestapu Reformasi: Serangkaian Kesaksian, Mizan, Jakarta, 2013

Sembilan Komandan Perang NU, Majalah Aula, November 2012, hal. 58-59.,

Muchith Muzadi, KH.Munasir Ali: Guruku dan Penuntunku. http://www.nu.or.id/a,publicm,dinamic-s,detail-ids,4-id,7256-lang,id-c,kolom-

t,KH+Munasir+Ali+Almarhum++Guruku+dan+Penuntunku-.phpx

Shaplen, Robert. Time out of hand: revolution and reaction in Southeast Asia. Harper \& Row, 1969.

Pour, Julius. Gerakan 30 September: pelaku, pahlawan \& petualang. Penerbit Buku Kompas, 2010.

May, Brian. The Indonesian Tragedy. Routledge \& K. Paul, 1978.

Sundhaussen, Ulf. The road to power: Indonesian military politics, 1945-1967. Oxford University Press, 1982. 
Sudjatmiko, Iwan Gardono. The destruction of the Indonesian Communist Party (PKI): a comparative analysis of East Java and Bali. Harvard University, 1992.

Feillard, Andree. NU vis-à-vis Negara: Pencarian Isi, Bentuk dan Makna. Lembaga Kajian Islam dan Sosial (LKiS), 1999.

Wieringa, Saskia. Kuntilanak wangi: organisasi-organisasi perempuan Indonesia sesudah 1950. Pusat Komunikasi dan Informasi Perempuan, 1998.

Fealy, Greg, and Greg Barton. "Wahab chasbullah, traditionalism and the political development of Nahdlatul Ulama." Nahdlatul Ulama, traditional Islam and modernity in Indonesia (1996): 1-41.

Feillard, Andrée. Islam et armée dans l'Indonésie contemporaine: les pionniers de la traditions. Vol. 28. Editions L'Harmattan, 1995.

Luhulima, James. Menyingkap dua hari tergelap di tahun 1965: melihat peristiwa G30S dari perspektif lain. Penerbit Buku Kompas, 2006.

Mawardi, Chalid. "Practica Politika NU: Mendajung Ditengah Gelombang." Iakarta: Iajasan Pendidikan Practica (1967).

Said Budairy, Ibu dari Banyak Pemuda Pergerakan, http://sbudairy.blogspot.com/2008/02/ibu-dari-banyak-pemuda-pergerakan.html

Said Budairy, Subchan ZE Tokoh Muda Aneka Citra, http://sbudairy.blogspot.com/2008/03/subchan-ze-tokoh-muda-aneka-citra_12.html Wieringa, Saskia. The perfumed nightmare: Some notes on the Indonesian women's movement. Institute of Social Studies, 1985.

Wieringa, Saskia Eleonora. Penghancuran gerakan perempuan: politik seksual di Indonesia pascakejatuhan PKI. Penerbit Galangpress, 2010.

Raid, Hasan. Pergulatan Muslim Komunis: Otobiografi Hasan Raid. LKPSM-Syarikat, 2001.

Moestahal, Achmadi. Dari Gontor ke Pulau Buru: Memoar H. Achmadi Moestahal. Syarikat, 2002.

Poesponegoro, Marwati Djoened, Nugroho Notosusanto, and Richard Z. Leirissa. Sejarah Nasional Indonesia: Zaman kuno. Vol. 2. PT Balai Pustaka, 2008. 
Selected Documents Relating to the 'September $30^{\text {th }}$ Movement" and Its Epilogue, Indonesia, No.1 (Apr., 1966) pp. 131-204, Southeast Asia Program Publication at Cornell University Misrawi, Zuhairi. Hadratussyaikh Hasyim Asy'ari: moderasi, keumatan, dan kebangsaan. Penerbit Buku Kompas, 2010.

Lekra dan Geger1965. Jakarta: SeriBukuTempo dan KPG

Anderson, Ben. "How did the Generals die?." Indonesia 43 (1987): 109-134.

Stanley, Penggambaran Gerwani Sebagai Kumpulan Pembunuh dan Setan (Fitnah dan Fakta Penghancuran Organisasi Perempuan Terkemuka, 1999

Djajengminardo, Wisnu. Kesaksian: memoir seorang kelana angkasa. Angkasa, 1999.

Basri, M. Hasan, and Choirul Anam. KHR As' ad Syamsul Arifin, riwayat hidup dan perjuangannya. Sahabat Ilmu, 1994. 